East Tennessee State University

Digital Commons@ East Tennessee State University

ETSU Faculty Works

Faculty Works

$3-5-2007$

\title{
Temperamental and Joint Attentional Predictors of Language Development
}

Brenda J. Salley

Wallace E. Dixon Jr.

East Tennessee State University, dixonw@etsu.edu

Follow this and additional works at: https://dc.etsu.edu/etsu-works

Part of the Child Psychology Commons

\section{Citation Information}

Salley, Brenda J.; and Dixon, Wallace E.. 2007. Temperamental and Joint Attentional Predictors of Language Development. MerrillPalmer Quarterly. Vol.53(1). 131-154. https://doi.org/10.1353/mpq.2007.0004 https://muse.jhu.edu/article/214491 ISSN: $1535-0266$

This Article is brought to you for free and open access by the Faculty Works at Digital Commons @ East Tennessee State University. It has been accepted for inclusion in ETSU Faculty Works by an authorized administrator of Digital Commons @ East Tennessee State University. For more information, please contact digilib@etsu.edu. 


\section{Temperamental and Joint Attentional Predictors of Language Development}

\section{Copyright Statement}

Copyright 2007 Wayne State University Press. This document was originally published in Merrill-Palmer Quarterly. 


\title{
Temperamental and Joint Attentional Predictors of Language Development
}

\author{
Brenda J. Salley, Virginia Polytechnic Institute and State University \\ Wallace E. Dixon, Jr., East Tennessee State University
}

\begin{abstract}
Individual differences in child temperament have been associated with individual differences in language development. Similarly, relationships have been reported between early nonverbal social communication (joint attention) and both temperament and language. The present study examined whether individval differences in joint attention might mediate temperament-language relationships. Temperament, language, and joint attention were assessed in 51 21 -month-olds. Results indicated an inverse relationship between aspects of temperamental difficulty, including low executive control and high negative affect, and language development. Temperamental aspects of negative affect were also inversely predictive of joint attention. However, the utility of a model in which joint attention mediates the relationship between temperament and language during the second year was not supported.
\end{abstract}

A growing body of literature has revealed relationships between children's temperament and their language development. Researchers have linked specific temperamental dimensions such as attention span and positive emotionality to both productive and receptive language, and they have

Brenda J. Salley, Department of Psychology, Virginia Polytechnic Institute and State University. Wallace E. Dixon, Jr., Department of Psychology, East Tennessee State University.

This work was supported by NIH/NICHD Grant HD043865 to the second author. Portions of these data were previously presented at the 2005 Meetings of the Society for Research in Child Development, Atlanta, Georgia. This project was completed in partial fulfillment of the requirements for the Master of Arts degree of the first author at East Tennessee State University. Thanks go to Andy Acuff, Stacy Barner, Michael Childress, Fran Chumney, Sonia Coney, Rima Gemayel, James Gorniewicz, Julia Hammons, Matt Lazenka, Sara Loudermilk, Nelly Ostrovsky, Rebecca Stanley, Nicole Stephens, and Josh Woodson for their help in data collection and analysis. Special thanks go to the parents and children who helped make this study possible.

Correspondence concerning this article should be addressed to Wallace Dixon, Department of Psychology, East Tennessee State University, P.O. Box 70649, Johnson City, TN, 37614. E-mail: dixonw@etsu.edu.

Merrill-Palmer Quarterly, January 2007, Vol. 53, No. 1, pp. 131-154. Copyright @ 2007 by Wayne State University Press, Detroit, MI 48201. 
done so repeatedly across multiple lab settings (Dixon \& Smith, 2000; Karrass, 2002; Matheny, 1989; Morales et al., 2000a; Slomkowski, Nelson, Dunn, \& Plomin, 1992). The general finding has been that children with aspects of temperamental easiness (i.e., affective positivity, long attention span) tend to be relatively linguistically advanced. Although the correlational nature of these studies makes it premature to draw conclusions with respect to directions of effect, a bidirectional influence seems reasonable. For example, just as heightened linguistic sophistication may contribute to ease of interpersonal communication and relatively positive affect as a result of successful communication, so too might temperamental positive affect contribute to increased opportunities for language acquisition. In the present study, we focus on the potential impact of temperament on language and consider ways in which temperament might be expected to influence language development.

Following the assumption that temperament contributes to language development, we must ask how it would do so. Rieser-Danner (2003) has postulated that temperament may have both direct and indirect impacts on language and cognitive functioning. In terms of a direct route of influence, children's difficult temperaments might simply limit the extent to which they can process linguistically relevant information during language acquisition events. This possibility is consistent with Rothbart and Bates (1998), who suggest that the attentional components of temperament form part of an overarching behavioral control system, which, as a function of anterior brain maturation, becomes increasingly weighted through early development with modulating dimensions of temperament associated with emotionality. Thus, when children are very high in general negative affectivity, a relatively greater burden is placed on their behavioral control systems, which must regulate this negative affectivity. The end result is fewer resources available for linguistically relevant activities such as paying attention to word-referent associations when learning novel labels. Consistent with Rothbart and Bates' hypothesis, a number of studies have reported that children who possess greater negative affect, higher response intensity, and lower tolerance for change of routine do in fact exhibit relatively short attention spans (e.g., Gartstein \& Rothbart, 2003; Karrass \& BraungartRieker, 2003; Smith et al., 1997), and these children also tend to have smaller vocabularies (Dixon \& Smith, 2000).

An alternative route of influence follows from the possibility that some aspects of children's temperament might indirectly contribute to language by influencing the formation of the social relationships that are relevant for language acquisition. That is, the kind and duration of interpersonal exchanges entered into by temperamentally difficult children may be dif- 
ferent than those entered into by easygoing children, and these interpersonal relationships may have differential consequences for language acquisition (cf. Rieser-Danner, 2003). The temperament to language route of influence in this case is indirect to the extent that temperament is mediated by relationship quality.

These pathways of influence are not necessarily mutually exclusive, and both may be partially responsible for contributing to language development. However, to our knowledge only two studies have directly examined either route of influence, and both of these have focused explicitly on the direct route (Dixon \& Salley, in press; Dixon, Salley, \& Clements, 2006). The premise of these studies was that because children's temperament cannot be manipulated directly, the next best thing would be to manipulate the environment in a way that would tap into children's temperament in theoretically relevant ways. Thus, in a laboratory setting, Dixon and colleagues distracted children while simultaneously teaching them novel words, with the expectation that the effect of the distracters on word learning would vary as a function of children's temperaments. Results of these studies were consistent with the direct-route approach. Children with the longest attention spans (as rated by either neutral observers or mother report) were least affected by the distracters and most likely to learn the novel words.

Importantly, other research suggests the importance of taking social relationships into account when exploring temperament-cognition associations. For example, Karrass and Braungart-Rieker (2004) reported that correlations between 1-year temperamental distress to novelty and 3-year IQ were moderated by security of mother-child attachment. Historically, temperament and language development have both been associated with social development (e.g., Carson, Klee, Perry, Muskina, \& Donaghy, 1998; Thomas, Chess, \& Birch, 1968), which raises the possibility that easygoing children are relatively socially skilled and are well positioned to establish high-quality social relationships that would place them at a linguistic advantage.

One aspect of children's social skills that may play a particularly central role in mediating temperament-language relationships is children's proclivity for engaging in joint attention. Researchers have consistently reported relationships throughout infancy and toddlerhood between joint attention and both language development (Markus, Mundy, Morales, Delgado, \& Yale, 2000; Mundy \& Gomes, 1998) and temperament (Kasari, Sigman, Mundy, \& Yirmiya, 1990; Vaughan et al., 2003). Thus, there is evidence that joint attention may play a mediating role in the temperamentlanguage relationship. However, to our knowledge no published research has explored whether correlations between temperament and language are a byproduct of their common relationship with joint attention. 
Joint attention as a means of nonverbal social communication is theorized to tap into social, emotional, and cognitive domains of development. It also reliably predicts a variety of sociodevelopmental outcomes, including IQ, social adaptation, behavioral regulation, and language development in both typically and atypically developing populations (Sheinkopf, Mundy, Claussen, \& Willoughby, 2004). In terms of its developmental significance, joint attention has been characterized as a specialized form of attention sharing and nonverbal communication that emerges as children first engage in eye-to-eye gaze with social partners, and it develops as children and their social partners coordinate attention toward common objects or events. Joint attention has been divided into two basic categories: (1) responding to joint attention (RJA) occurs when one follows the direction of eye gaze, head turn, or pointing gesture of a social partner (Mundy, Hogan, \& Doehring, 1996), whereas (2) initiating joint attention (IJA) occurs when one points or looks at an interesting object or event while alternating gaze between the object and a social partner (Mundy et al., 1996). Joint attention is most often operationally defined either by the amount of time spent in mutual object engagement in naturalistic settings or by experimentally induced behaviors (i.e., eye gaze following or pointing in response to experimenter prompts).

Researchers have primarily focused on understanding how joint attention facilitates language development (Carpenter, Nagell, \& Tomasello, 1998; Dunham \& Dunham, 1992; Dunham, Dunham, \& Curwin, 1993; Morales et al., 2000a; Tomasello \& Farrar, 1986), and it is easy to conceptualize how it might do so. Baldwin (1995), for example, demonstrated that when 18-month-old children and an adult experimenter were looking at two different novel objects and the adult applied a novel word to her own object, children would learn the novel label for the experimenter's object rather than identifying the label with their own object. In this case, children had to attend to the experimenter's attentional focus in order to learn the target word-referent mapping.

In a longitudinal study of joint attentional behaviors from 6 to 24 months, Morales et al. (2000b) found that responding to joint attention at 6 , $8,10,12$, and 18 months positively predicted vocabulary development at 2 years. Moreover, several studies have demonstrated that the amount of time children spent sharing attention with others predicted their later vocabulary development and even their later IQ (Markus et al., 2000; Mundy \& Gomes, 1998; Tomasello \& Farrar, 1986; Ulvund \& Smith, 1996).

There are good reasons to expect that individual differences in the development of joint attention may partially derive from individual differences in child temperament. Vaughan et al. (2003) reported that IJA at 9 
months was positively associated with 9-month smiling and laughter. This finding makes sense to the extent that positive emotionality should provide an emotional scaffold for children to develop skill in allocating joint attention and to develop an appreciation for interpersonal exchanges generally. Interestingly, Vaughan et al. also found that 9-month distress to novelty was positively predictive of IJA bids at 12 months. To account for this seemingly contradictory finding, Vaughan et al. suggested that children who are inhibited by novelty may use joint attention bids with familiar caregivers as a means to gather social information to allay their distress. In other words, under some conditions IJA may serve a social referencing function in the service of stress reduction. In this way, temperamental predispositions may contribute to the development of joint attention.

Although past research raises the possibility of an indirect route of influence, from temperament to social relationship quality to language development, the nature of such a relationship has not been investigated. We propose to test this model by exploring both the relationships between temperament and joint attentional skills and the relationships between joint attentional skills and language development, under the assumption that joint attentional skills contribute to the development of linguistically relevant social relationships. The following hypotheses were considered.

First, in replication of previous research, we expected that infant temperament would predict concurrent measures of vocabulary at age 21 months (Dixon \& Shore, 1997; Dixon \& Smith, 2000; Morales et al., 2000a). To this end, dimensions of temperament previously found to predict language productivity, namely attention span, positive emotionality, adaptability/soothability, and perceptual sensitivity, were expected once again to associate with language productivity. Extending previous research, the correlations were expected to obtain with a different mother-report temperament instrument than previously used - that is, the Early Child Behavior Questionnaire, or ECBQ (Putnam, Jones, \& Rothbart, 2002)—and a different, predominantly rural sample of children. Because the ECBQ is a new instrument developed to tap into more fine-grained dimensions of temperament than previously explored, we were also interested in whether any of the newly conceptualized dimensions of temperament might correlate with language development.

Second, we expected 21-month joint attention to be related to concurrent temperament (Morales et al., 2000a; Mundy, Kasari, \& Sigman, 1992; Vaughn et al., 2003). In particular, aspects of temperament thought to promote social relationships, such as attention span, positive mood, and adaptability, were expected to correlate positively with children's joint attentional skills. Similarly, aspects of temperament thought to inhibit 
social relationships, such as fear of novelty, negative mood, and inhibition, were expected to correlate negatively with children's joint attentional skills. In contradistinction to Vaughan et al. (2003), who found a positive relationship between distress to novelty and IJA in the context of familiar child-caregiver dyads at 12 months, we expected the opposite association as a function of our incorporation of unfamiliar child-experimenter dyads. In other words, we expected high levels of discomfort with novelty to associate with low levels of joint attention in the presence of an unfamiliar social partner.

Finally, the primary purpose of this investigation was to examine the extent that links between temperament and language were attributable to children's joint attentional skills. Because we viewed it as conceivable that the temperament-language relationships reported in the literature were an artifact of joint attentional skill, we sought to determine the extent to which temperament-language relationships would be attenuated when variance due to joint attentional skill was removed. Implicit in this hypothesis was that infant joint attention at 21 months need not be associated with concurrent measures of language facility. Past research has failed to find a concurrent correlation between joint attention and vocabulary size beyond 18 months (Morales et al., 2000b), which suggests that although early joint attentional skill may facilitate subsequent language development, later joint attentional skill may not associate with concurrent language facility. Nevertheless, it remained of interest to explore whether temperament remained correlated with language after controlling for joint attention.

\section{Methods}

\section{Participants}

For this study, 21-month-old toddlers $(M=21.88$ months, $S D=0.36$ months) were recruited through birth announcements placed in local newspapers. Fifty-one participants volunteered from a rural, upper SES Appalachian community. With the exception of one boy who was identified by his mother as having a non-European American father, $98 \%$ of the sample self-identified as European American in ethnicity ( 21 boys and 30 girls). Mean maternal age was 32.00 years ( $S D=5.90$ years), with fathers averaging 33.34 years $(S D=5.72)$. Annual household income ranged from a low of $\$ 13,000$ to a high of $\$ 250,000$, with a median income of $\$ 66,000$. Forty-eight children were accompanied to the lab by their mothers, three by their fathers. Children and their caregivers participated in a session conducted at the infant studies laboratory on the campus of a regional univer- 
sity. Parents were informed that they would be participating in a one-time study on the relationship between temperament and language development. Parents were then requested to schedule their visit for a time during which their child would typically be alert and wakeful. Children selected a \$5-10 toy in exchange for their participation.

\section{Materials}

Early Childhood Behavior Questionnaire. The ECBQ (Putnam et al., 2002) was used to assess parent report of temperament. Its 201 items describe daily behaviors that take place during typical events such as naptime (e.g., "When told that it is time for bed or a nap, how often did your child [a] react with anger or [b] get irritable?") and peer interactions (e.g., "When approaching unfamiliar children playing, how often did your child [a] watch rather than join in, [b] approach slowly, or [c] seem uncomfortable?"). For each of the items, response options ranged from 1 ("never") to 7 ("always"). A list of the 18 ECBQ subdimensions along with its 3 superdimensions can be found in Table 1 .

Parent report has been found to be a reliable means for the assessment of children's temperament (Rothbart \& Bates, 1998) and has the added advantage that parents are likely to have the best and widest access to observing their children's temperamental expression (Putnam, Ellis, \& Rothbart, 2001). In addition, parent report has been validated against children's actual laboratory behavior (e.g., Bridges, Palmer, Morales, Hurtado, \& Tsai, 1993; Goldsmith \& Rothbart, 1991; Smith et al., 1997).

It should be pointed out that a driving force in the psychometric construction of the ECBQ (and other instruments from the same family such as the Infant Behavior Questionnaire-Revised and the Child Behavior Questionnaire), is Rothbart and colleagues' (e.g., Putnam et al., 2001; Rothbart \& Bates, 1998) comprehensive model of children's temperament. Their model generally comprises three overarching constructs, derived from factor analyses, believed to characterize children's temperament from early infancy through early adolescence. Each of these overarching factors in turn comprises a number of subscales or more fine-grained aspects of temperament. Their factors include surgency, negative affect, and executive control. Surgency is taken as an index of the degree to which children are generally outwardly focused or outgoing and may characterize the extent to which children engage in appetitive behaviors. Included in surgency are subscales reflecting aspects of positive emotionality. Negative affect is designed to reflect the extent of activation of children's fear and stress systems and is typically manifested in withdrawal behaviors. Finally, effortful control gives 
Table 1. Means, Standard Deviations, and Internal Reliabilities for ECBQ Dimensions

\begin{tabular}{lrrr}
\hline ECBQ Dimension & $M$ & \multicolumn{1}{c}{$S D$} & $\alpha$ \\
\hline Executive Control & & & \\
Affiliation & 4.63 & .75 & .81 \\
Aftentional focusing & 3.93 & 1.02 & .87 \\
Aftention shifting & 4.75 & .63 & .48 \\
Inhibitory control & 3.75 & 1.02 & .91 \\
Low-intensity pleasure & 5.05 & .94 & .75 \\
Surgency & & & \\
Activity level & 4.37 & .84 & .75 \\
High-intensity pleasure & 4.71 & .91 & .81 \\
Impulsivity & 4.76 & .77 & .74 \\
Positive anticipation & 4.75 & 1.05 & .86 \\
Sociability & 5.79 & .95 & .81 \\
Negative Affect & & & \\
Discomfort & & & \\
Fear & 2.22 & .83 & .73 \\
Frustration & 2.20 & .74 & .68 \\
Motor activation & 3.20 & 1.05 & .85 \\
Perceptual sensitivity & 2.10 & .73 & .74 \\
Sadness & 4.27 & 1.18 & .88 \\
Shyness & 2.56 & .85 & .78 \\
Soothability & 3.05 & 1.07 & .87 \\
\hline Note: N 49 & 5.18 & .72 & .82 \\
\hline
\end{tabular}

Note: $\mathrm{N}=49$ for available ECBQ data.

"children the ability to direct their attention, to choose between an array of competing choices, and to regulate their emotions and behaviors" (Putnam et al., 2001, p. 178). These three broad factors have been cross-culturally identified as remaining stable in studies of infants, children, and adolescents (Putnam et al., 2001, 2002; Rothbart, Chew, \& Gartstein, 2001).

MacArthur-Bates Communicative Development Inventory. Measures of language productivity were also obtained from parent report via the MacArthur-Bates Communicative Development Inventory, Words and Sentences version, or MBCDI (Fenson et al., 1994). The MBCDI Words and Sentences yields measures of productive vocabulary and morphological 
development, as well as an estimate of the mean length of utterance (MLU) of children's parent-reported longest three utterances for children between 16 and 30 months of age. From a series of word lists drawn from categories representing nouns, verbs, pronouns, and several other form classes, parents are asked to identify the words their children produce. This instrument has demonstrated high internal consistency and test-retest reliability (Fenson et al., 1994). Based on a review of studies examining the validity of parent report of child vocabulary in general and the validity of the MBCDI specifically, Fenson et al. (1994) concluded that the MBCDI reliably assesses a more complete range of vocabulary production than either laboratory observation or structured laboratory measures allow. For purposes of succinctness, summary measures of the MBCDI were employed and included nouns, predicates, closed-class items, and morphology.

Early Social Communication Scales. To measure children's joint attention bids and responses in our sample, we adapted the Early Social Communication Scales, or ESCS Abridged (Mundy et al., 2003), which focuses on children's eye contact and gestural communication. The ESCS has been validated to measure early nonverbal communicative development for children 8 to 30 months of age.

Among the three categories of nonverbal social communication skills that the ESCS has been designed to assess, for the present study we employed only the joint attentional measures (IJA \& RJA). Both naturally occurring and experimentally induced behaviors were coded for frequency of occurrence from split-screen video recordings of both child and experimenter eye-gaze activity. IJA bids were counted when children pointed at or alternated gaze between an interesting object or event and a social partner (i.e., either the parent or the experimenter) or showed an object to a social partner. RJA bids were counted whenever children followed the direction of eye gaze, the head turn, or the pointing gesture of the experimenter.

Two ESCS tasks were adapted and presented to each child. First, the Book Task assessed both IJA and RJA behaviors. For this task, a picture book (with several large, brightly, colored pictures on each $8.5 " \times 11 "$ page) was displayed in front of the child. The experimenter allowed the child to explore the book uninterrupted for approximately 20 seconds. If the child spontaneously pointed to pictures in the book, the experimenter responded naturally and briefly (e.g., "I see"). After the initial 20 seconds elapsed, the experimenter began pointing to pictures, using the child's name while pointing. On each page, up to four pictures were pointed out by the experimenter, with each consecutive picture being of sufficient distance from the previous picture so that any shift in visual focus could be easily observed. This process was repeated for each page in the picture book. 
Second, the Attractive Toy Task was designed to elicit IJA behaviors. The task began when an attractive windup toy (Gary the Snail) was shown to the child. The experimenter wound the toy, placed it out of the child's reach, and let it run across the table in front of the child. Joint attention initiation bids by the child were again responded to naturally and briefly. The experimenter then placed the toy in a clear plastic container, sealed it so that children could not gain access to the toy, and handed the container to the child. For the next minute, the experimenter left the room. The experimenter's absence provided children with an opportunity to engage their parents with IJA bids.

Following Mundy and Gomes (1998), IJA bids were classified as either developmentally higher- or lower-level behaviors. Lower-level IJA bids included eye contact with the experimenter while the child manipulated or touched a target object and alternates, in which the child shifted gaze between the target object and the eyes of either the experimenter or the parent. Higher-level IJA bids included pointing, in which the child pointed to the target object before observing any pointing on the part of an adult, and showing, in which a child held up an object for the visual regard of an adult. Across both tasks, IJA bids were counted whenever the child pointed or showed an object to the experimenter or parent while making eye contact (higher IJA) or when the child made eye contact or alternated eye contact with the experimenter or parent without pointing or showing (lower IJA). RJA was only counted in the Book Task and reflected the extent to which children followed the pointing gestures of the experimenter. RJA was distinguishable from lower-level IJA alternates because RJA was counted only if children looked at a picture that the experimenter just pointed to. Two observers double-coded all videos, and a third coder made the final determination in the instance of disagreements.

\section{Design and Procedure}

One week prior to their visit, parents received by mail the ECBQ (Putnam et al., 2002) and the MBCDI (Fenson et al., 1994). Completed questionnaires were collected at the time of the lab visit. Parents remained with their children throughout the entire laboratory session, with children sitting on their parents' laps. The entire experimental session, including tasks not related to the present study, lasted about an hour.

Upon initial arrival, children were given the opportunity to acclimate to the setting while parents were consented. Women experimenters blind to children's temperament status administered the experimental sessions. About 8 minutes of the total session was devoted to the joint attention tasks. Order of 
the two joint attention tasks was counterbalanced across children. Data collection took place in a room measuring approximately 3 meters by 4 meters that contained a testing table and a cabinet holding the stimulus materials.

\section{Results}

Means and standard deviations for the temperament, language, and joint attention measures are reported in Tables 1, 2, and 3, respectively. Reliabilities for the ECBQ subdimensions are provided in Table 1. In Table 3, IJA bids were averaged across the two tasks. The sample data were compared to normative data for the ECBQ and MBCDI measures; however, normative ESCS data for 21 month olds were not available. Toddlers in the present study were at the mean for all language measures but were significantly above the mean for the ECBQ (temperament) scales of attention and attentional shifting. The source of this difference is not clear. Household income of families in the present study $(M=\$ 67,671)$ was roughly comparable to that of the ECBQ standardization sample $(M=\$ 59,158)$. For all other variables in the present sample, no significant differences from the normative samples were observed.

Although internal reliabilities for the ECBQ subdimensions were relatively good, two scales were noticeably lower than the others: attention shifting and fear. Low internal reliabilities of these scales may have constrained their correlations with the other variables. Summary language measures from the MBCDI are presented in Table 2. These include nouns (summing across all noun categories), predicates (summing the verb and adjective categories), closed class words (summing across all function word categories including pronouns, articles, and prepositions), morphology (summing across categories indexing children's use of noun and verb inflections), and MLU (mean length of utterance in morphemes). Although

Table 2. Means and Standard Deviations for MBCDI Summary Categories

\begin{tabular}{lrr}
\hline MBCDI Summary Category & \multicolumn{1}{c}{ M } & \multicolumn{1}{c}{$S D$} \\
\hline Nouns & 115.06 & 83.89 \\
Predicates & 42.51 & 42.78 \\
Closed class words & 17.04 & 20.82 \\
Morphology & 8.27 & 10.71 \\
Total vocabulary (nouns, predicates, closed class) & 174.62 & 40.61 \\
Mean length of utterance (MLU) & 3.02 & 1.81 \\
\hline
\end{tabular}

Note: $\mathrm{N}$ ranges from 43 to 47 for available MBCDI data. 
Table 3. Means and Standard Deviations for Joint Aftention Measures

\begin{tabular}{lrc}
\hline ESCS Behavior & $M$ & $S D$ \\
\hline IJA eye contact & 1.63 & 2.30 \\
IJA alternates & 1.35 & 1.52 \\
IJA points & 5.55 & 5.13 \\
IJA points with eye contact & .71 & 1.30 \\
Lower IJA (eye contact + alternates) & 3.04 & 3.28 \\
Higher IJA (points + points with eye contact) & 6.25 & 5.74 \\
Total IJA (lower IJA + higher IJA) & 9.52 & 6.51 \\
Ratio higher IJA/total IJA & .64 & .32 \\
RJA ratio points followed & .70 & .20 \\
\hline
\end{tabular}

the standard deviations for the language measures appear large relative to their means, it is important to point out that this is typical of the variability in productive vocabulary at this age and is in fact comparable to previous work (e.g., Dixon \& Smith, 2000).

Across all possible temperament, language, and joint attention measures, only two gender differences emerged: boys were rated significantly higher than girls in level of discomfort $(t[43]=2.00, p=.052)$, and they were reported as producing fewer closed class words (e.g., pronouns, articles, prepositions) than girls $(t[45]=-2.03, p=.049)$.

\section{Temperament and Language}

The first question of interest dealt with whether the temperament subscales were associated with children's language. Based on past research, it was expected that ECBQ subscales of attention span, positive emotionality, soothability (e.g., Dixon \& Shore, 1997; Dixon \& Smith, 2000) and perceptual sensitivity (Dixon \& Smith, 2000) would correlate positively with measures of language development. With respect to the ECBQ, therefore, we expected that language measures would correlate with attention span measures (attentional focusing, attention shifting, and inhibitory control), positive emotionality measures (low-intensity pleasure, high-intensity pleasure, and positive anticipation), sociability, and perceptual sensitivity.

Table 4 shows the temperament-language correlations. Because there were 21 possible temperament measures ( 18 subscales +3 factors), an individual temperament measure was included in the table only if (a) it was pre- 
dicted to correlate with the language measures or (b) 2 or more of its correlations with the language measures were significant at the $\alpha=.10$ level. With correlational analyses, it is important to be cautious regarding experiment-wise error rates. In the present case, however, there were 63 correlations that emerged as statistically significant at the .10 level, which is four times what would be expected by chance-clearly indicating meaningful relationships between the temperament and language measures.

With the exception of sociability, language measures were significantly correlated with all of the predicted temperament dimensions. Dimensions of attention were most robustly associated with the language measures. Surprising on this account was the fact that among the attention measures associated with language was attention shifting. Recall that internal reliability of this measure in our sample was especially low. Positive anticipation and perceptual sensitivity were also correlated with the majority of the language measures; however, correlations between language and high- and low-intensity pleasure appeared much more sporadic and relatively weak.

Two measures of temperament were unexpectedly correlated with language. Frustration and sadness, both aspects of the negative affect superdimension, were significantly negatively correlated with measures of language. Such inverse correlations were anticipated but did not obtain in previous research, such as in Dixon and Smith (2000). From the perspective of either the direct or the indirect route of influence model, it stands to reason that children with high levels of negative affect would be at a language-learning disadvantage, but it is not clear why similar findings were not obtained in previous work.

\section{Joint Attention and Temperament}

Based on past research, it was predicted that children high in aspects of positive emotionality would demonstrate relatively well-developed joint attentional skills. But in the present study it was also predicted that children high in negative emotionality would demonstrate relatively low levels of joint attentional skill, because it was expected that they would have experienced relatively few social learning opportunities to acquire well-developed ones. Finally, we anticipated that children's high dimensions of attention would generally be at an advantage for developing joint attentional skill if for no other reason than that both temperamental attention and joint attention might draw on a common attentional function.

As can be seen in Table 5, our predictions were not strongly confirmed. In the one instance where a measure of positive emotionality was correlated (i.e., positive anticipation), the correlation was opposite the expected direction. 


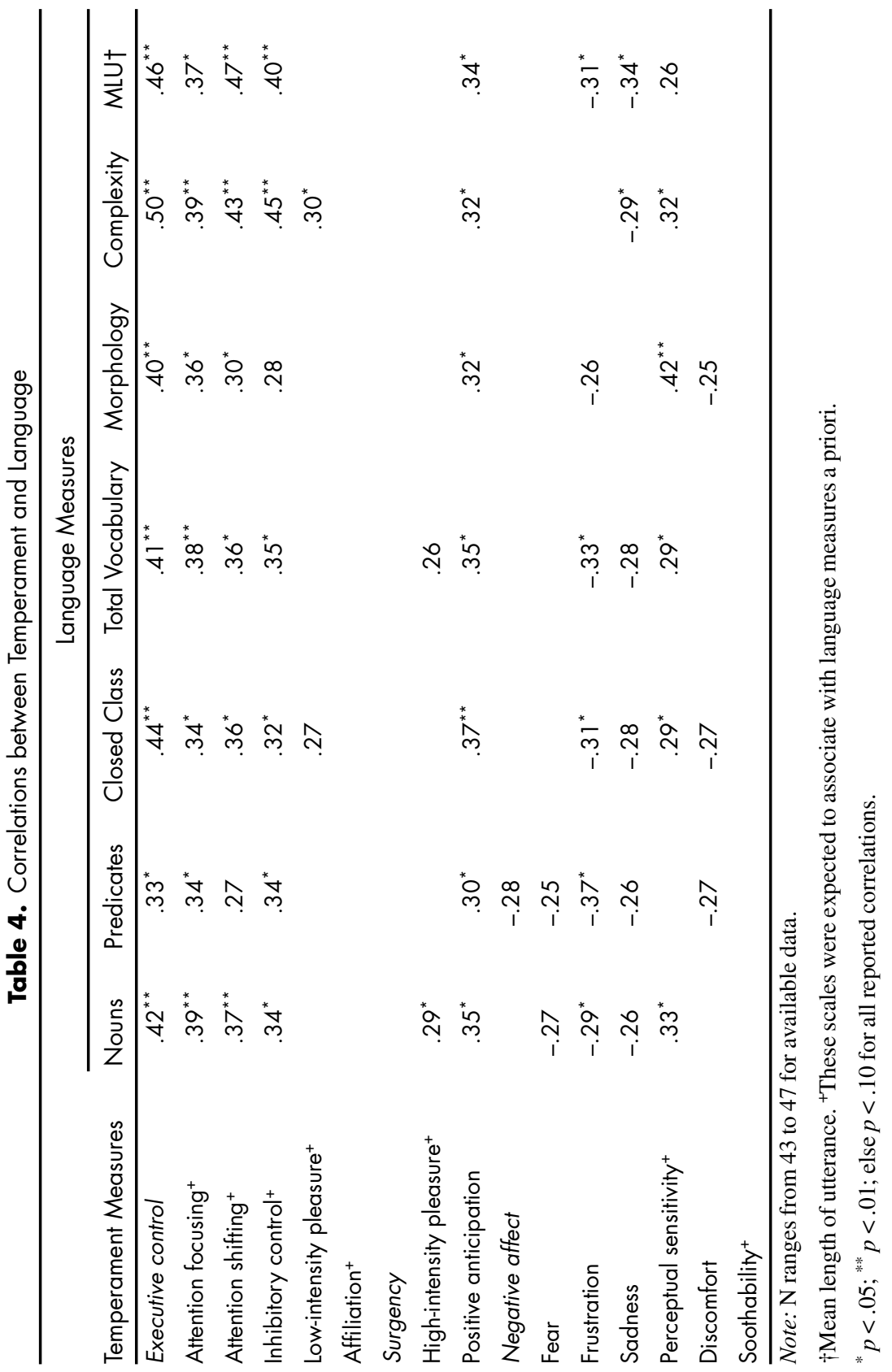




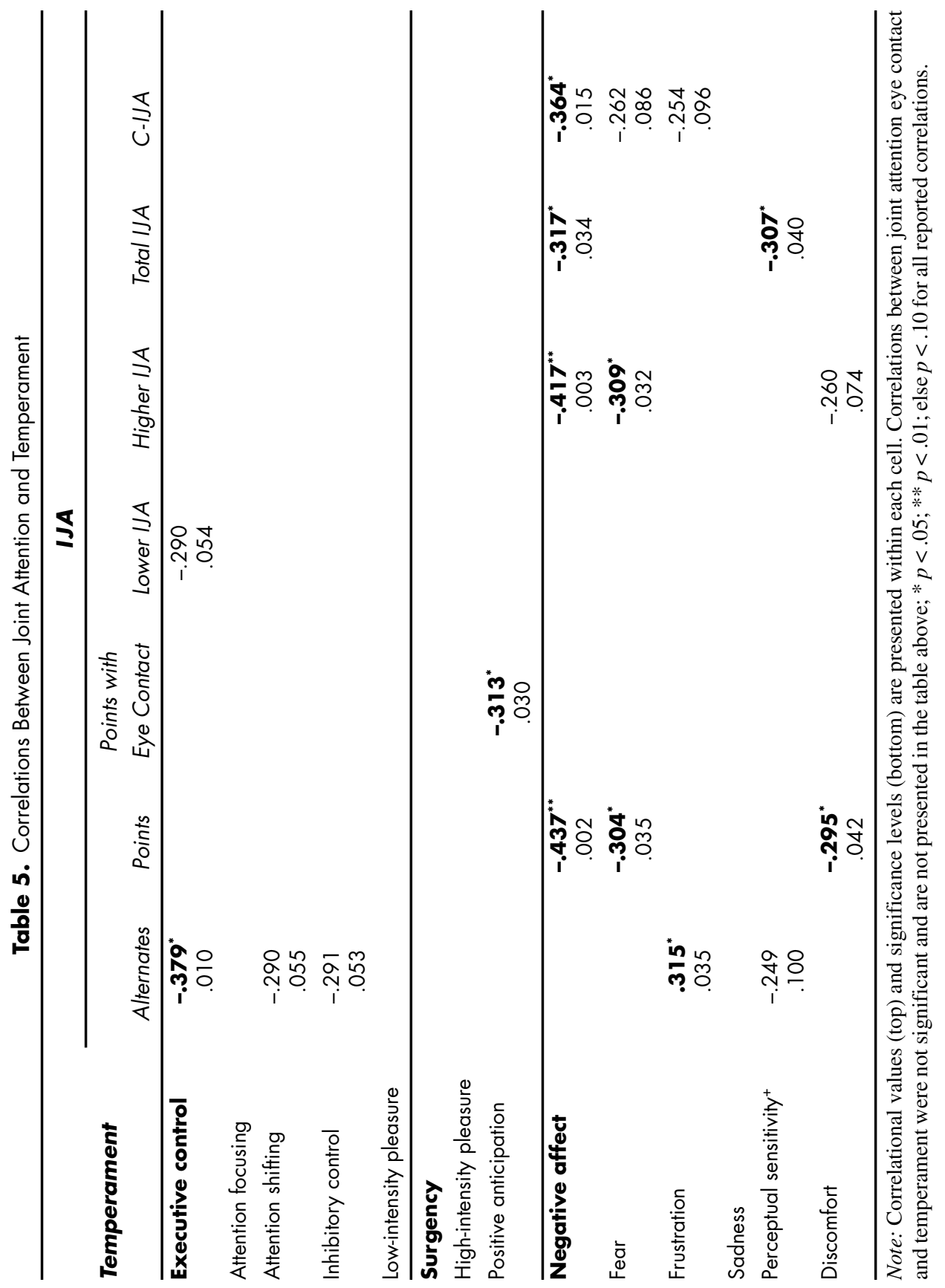


Similarly, attention span measures were correlated with primarily one joint attention measure (i.e., IJA alternates), but again, these correlations were opposite the expected direction.

Confirming expectations was the pattern of correlations involving joint attention and negative emotionality. Toddlers low in frequency of pointing were generally higher in fear and discomfort. Again, however, not all dimensions were in the predicted direction. For example, higher frustration was predictive of a higher frequency of IJA alternates. Interestingly, perceptual sensitivity was correlated with overall IJA, which suggests that children who were least sensitive to ongoing environmental activity were most likely to engage in joint attention. RJA was not correlated with any of the temperament measures and so is not included in Table 5.

Considering experiment-wise error, the correlational analyses involving joint attention and temperament would produce about 10 falsely significant correlations. However, 18 significant correlations obtained, suggesting that the pattern of associations are meaningful. The negative affect factor seemed to best predict children's likelihood of engaging in joint attention. Consistent with the direction of the majority of the correlations with the temperament subdimensions, high levels of negative affect were generally associated with lower levels of IJA bids.

\section{Joint Attention, Language, and Temperament}

The primary goal of the present investigation was to explore whether individual differences in children's temperament remained correlated with individual differences in vocabulary size, after controlling for joint attention. As an exploratory first step toward testing this possibility, we conducted correlational analyses between joint attention and total vocabulary. Consistent with Morales et al. (2000b), we found that joint attention measures failed to associate with vocabulary at 21 months of age. Next, because dimensions of negative emotionality were correlated with both joint attention and vocabulary, we wondered whether negative emotionality would continue to correlate with vocabulary after statistically controlling for joint attention. Unfortunately, this analysis was obviated by the fact that the measures of negative affect that correlated with joint attention were generally not the same ones as correlated with the vocabulary measure (with the exception of frustration and perceptual sensitivity). In an effort to determine whether vocabulary would correlate with negative affectivity after controlling for joint attention (i.e., IJA alternates), a regression analysis was conducted in which frustration and perceptual sensitivity were regressed simultaneously on both total vocabulary and the joint attention measure with which they were most highly correlated. As 
Table 6. Simultaneous Regressions of Temperament Measures on Total Vocabulary and Joint Attention Measures

\begin{tabular}{llrrc}
\hline Dependent Variable & Independent Variables & \multicolumn{1}{c}{$B$} & \multicolumn{1}{c}{$t$} & \multicolumn{1}{c}{$p$} \\
\hline 1. Executive control & Total vocabulary & .44 & 3.28 & .002 \\
& Lower IJA & -.32 & -2.39 & .022 \\
2. Executive control & Total vocabulary & .38 & 2.85 & .007 \\
& IJA alternates & -.34 & -2.56 & .015 \\
3. Attention shifting & Total vocabulary & .31 & 2.14 & .038 \\
& IJA alternates & -.26 & -1.80 & .080 \\
4. Inhibitory control & Total vocabulary & .36 & 2.54 & .015 \\
& IJA alternates & -.25 & -1.79 & .082 \\
5. Positive anticipation & Total vocabulary & .33 & 2.45 & .018 \\
& IJA pointing & -.31 & -2.25 & .029 \\
6. Frustration & Total vocabulary & -.26 & -1.80 & .079 \\
& IJA alternates & .29 & 2.03 & .049 \\
7. Perceptual sensitivity & Total vocabulary & .33 & 2.30 & .027 \\
& Total IJA & -.37 & -2.58 & .014 \\
\hline
\end{tabular}

shown in Table 6 , the language-temperament correlation remained significant even after controlling for the IJA measure.

In fact, there were only five other cases in which a temperament measure was correlated simultaneously with both a joint attention and a language measure. Each of these cases was subjected to a regression analysis similar to that employed with the negative affect measures, and in each case the temperament measure remained correlated with total vocabulary after controlling for joint attention (see Table 6). Based on these data, it appears that correlations between temperament and concurrent language are probably not an artifact of their joint attentional skills at 21 months of age.

\section{Discussion}

The overarching goal of the present study was to explore the hypothesis that temperament may have an indirect route of influence on language development by virtue of its intermediary effect on children's abilities to construct or maintain linguistically supportive social relationships. Nonverbal social communication, as a theoretical foundation for social relationships, was operationalized as children's expression of initiating or responding to 
joint attentional bids in a laboratory setting. Although as expected that measures of temperament were robustly predictive of language development, children's expression of joint attention was generally not correlated with concurrent measures of language development at 21 months of age. Measures of temperamental negative affect were found to correlate with both joint attention and language measures, findings that represent additions to the literature. However, partialing out the variation in temperament due to joint attention appeared to have no effect on correlations between temperament and language. Thus, it appears that temperament-language relationships at this age exist over and above any contributions to the covariance made by joint attention.

We believe that these results make several important contributions to the literature. First, they add to the growing literature demonstrating a link between individual differences in temperament and individual differences in language. In line with past research (Dixon \& Smith, 2000; Karrass \& Braungart-Rieker, 2003; Kubicek, Emde, \& Schmitz, 2001; Matheny, 1989; Slomkowski et al., 1992), aspects of positive emotionality were associated with language ability in the present study. Specifically, pleasure in expectation of enjoyable activities, along with the pleasure and positive mood expressed during a high-intensity experience, were predictive of better language ability.

But in addition, the present results are among the first to reveal an association between aspects of negative emotionality and language development. The specific subscales of temperament that many parents might regard as characterizing temperamental difficulty-namely fear, frustration, sadness, and discomfort-were, as a group, associated with aspects of relatively poor language development. These results are consistent with Rothbart and Bates's (1998) control systems approach (also consistent with a direct-route-of-influence model), which posits that children high in negative affectivity would allocate considerable attention toward regulating their negative affectivity and would consequently have fewer attentional resources to allocate to language acquisition.

The present results are also consistent with previous literature in failing to find a relationship between RJA and language in the second half of the second year (Morales et al., 2000b). Most researchers agree that the complete range of joint attention skills appears to come under the control of the child sometime between 12 and 18 months of age (Adamson \& MacArthur, 1995; Tomasello, 1995). However, to the extent that most children have developed considerable joint attentional skill by the end of the second year, individual differences in the employment of joint attention may cease to be predictive of individual differences in vocabulary or morphological devel- 
opment. Perhaps joint attentional skill, particularly RJA skill, reaches a ceiling by 21 months of age and loses its predictive utility in accounting for vocabulary development as a result. A next step in this line of research might be to explore whether joint attentional skill at 21 months of age predicts performance in still more sophisticated language domains such as grammar or pragmatics, either concurrently or longitudinally. To the extent that RJA is considered to be developmentally earlier than IJA, these latter correlations might be expected to reflect primarily IJA-language correlations rather than RJA-language ones.

The fact that IJA bids were negatively associated with the affectively negative dimensions of temperament and not positively associated with the affectively positive dimensions of temperament was unexpected. Based on previous research, we anticipated that temperamental dimensions of positive emotionality would be related to higher frequencies of joint attentional bids (Morales et al., 2000a; Mundy et al., 1992; Vaughn et al., 2003), but this expectation was not fulfilled. Discovery that temperamentally negative children engage in few joint attentional bids, coupled with the absence of any association between positive emotionality and joint attention, may be a function of theoretical and empirical independence of the temperamental dimensions of negative and positive emotionality (cf. Putnam et al., 2002) in the temperament assessment instrument that we employed. We can at least say that children high in negative affect may be disadvantaged with respect to the employment of joint attentional skills under novel laboratory conditions.

It may be of some utility for future researchers to explore the extent that various subdimensions of negative affect differentially predicts joint attention or vocabulary development. It is curious, for example, that the negative affect factor was correlated with total IJA bids, whereas only the subscales of negative affect were associated with the language measures. This finding raises the possibility that various subdimensions of negative emotionality differentially map onto linguistic or joint attentional development. To test this hypothesis experimentally, and following upon Dixon and colleagues (Dixon \& Salley, in press; Dixon et al., 2006), research could be conducted in which children are taught novel words under variously threatening laboratory conditions. In an unfamiliar laboratory with an unfamiliar experimenter, children high in fear of novelty might be less successful than children low in fear of novelty in paying attention to information relevant for acquiring a novel label for a novel object and would instead allocate proportionally more attention to monitoring the proximal distance of the experimenter from the child. This prioritizing of attention might then result in poorer word learning among temperamentally fearful 
children. Other subscales of negative affect such as frustration or sadness would presumably be less relevant than fear for predicting the kind of information acquired by children in a novel setting, which may help explain why the negative affect factor is not consistently a robust predictor of language development.

A central limitation of the present study is its cross-sectional focus on 21 month olds. Considering longitudinal relationships among joint attention, temperament, and language development would be further illuminating. The predictive relationships between joint attention and language development reported in the literature are strongest in the latter half of the first year and the beginning of the second year, so it may be that to the extent that temperament has an impact on the development of children's joint attentional skill, it does so in the first 18 months. The relationship between joint attention and some of the affective dimensions of temperament may also be stronger during this time frame to the extent that children's executive control systems are presumably still developing, as are their abilities to use their executive control systems to override their more reactive socioemotional tendencies (Rothbart \& Bates, 1998; Smith et al., 1997).

It would also be useful to extend the procedures employed in the present study to more naturalistic settings. Joint attention assessed within naturally occurring mother-child interactions may be very different than that assessed in structured laboratory settings. For example, joint attention may be disproportionately affected by temperament in the laboratory setting when the lab is perceived by children as novel and frightening (or conversely attractive and exciting). Under these conditions, children high in negative affect (or surgency) to disproportionately would likely express their negative affect (or surgency) relative to what they would express in more familiar settings. Such differential expression of negative affect (surgency) might then differentially limit children's opportunities to engage in joint attention across the two settings.

There is considerable need for future research to move toward more structured experimental manipulations with an aim toward narrowing the range of possible explanations for potential temperament-language relationships. The extant literature linking temperament to both language and joint attention has been almost exclusively correlational in nature, locking temperament $\rightarrow$ language and temperament $\rightarrow$ joint attention into heuristic rather than causal models with limited supporting data. Controlled laboratory studies in which children with varying types of temperament are taught novel words in the laboratory under conditions that should theoretically tap into those dimensions of temperament would be especially useful. For example, in an adjunct of the hypothetical study just described, children 
high in fear and low in frustration could be randomly assigned to learn novel words under fear-provoking, frustration-inducing, or neutral conditions. The performance of these children could then be compared to children high in frustration and low in fear who were exposed to the same three conditions. If specific aspects of negative affect played a causal role in vocabulary acquisition, consistent with a direct route of temperament to language influence, then high-fear children should perform most poorly in fear-producing conditions, whereas high-frustration children should perform most poorly in frustration-inducing conditions.

Perhaps only through experimental manipulations such as these will the field move beyond a simple correlational level of understanding to one that has practical applications for children's everyday lives. Indeed, a thorough understanding of temperament-joint attention-language relationships will likely emerge only as a result of the efforts of multiple labs employing multimethod, multiage, and multidomain procedures in the name of establishing convergent validity to account for temperament-language relationships and their relationship to joint attention.

\section{References}

Adamson, L. B., \& McArthur, D. (1995). Joint attention, affect, and culture. In C. Moore \& P. J. Dunham (Eds.), Joint attention: Its origins and role in development. Hillsdale, NJ: Erlbaum.

Baldwin, D. A. (1995). Understanding the link between joint attention and language. In C. Moore \& P. J. Dunham (Eds.), Joint attention: Its origins and role in development (pp. 131-158). Hillsdale, $\mathrm{NJ}$ : Erlbaum.

Bridges, L. J., Palmer, S. A., Morales, M., Hurtado, M., \& Tsai, D. (1993). Agreement between affectively based observational and parent-report measures of temperament at infant age 6 months. Infant Behavior and Development, 16, 501-506.

Carpenter, M., Nagell, K., \& Tomasello, M. (1998). Social cognition, joint attention, and communicative competence from 9 to 15 months of age. Monographs of the Society for Research in Child Development, 63, No. 4 (Serial No. 255).

Carson, D. K., Klee, T., Perry, C. K., Muskina, G., \& Donaghy, T. (1998). Comparisons of children with delayed and normal language at 24 months of age on measures of behavioral difficulties, social and cognitive development. Infant Mental Health Journal, 19, 59-75.

Dixon, W. E., Jr., \& Salley, B. J. (in press). "Shhh! We're tryin' to concentrate": Attention and environmental distracters in novel word learning. Journal of Genetic Psychology. 
Dixon, W. E., Jr., Salley, B. J., \& Clements, A. D. (2006). Temperament, distraction, and learning in toddlerhood. Infant Behavior and Development, 29, 342-357.

Dixon, W. E., Jr., \& Shore, C. (1997). Temperamental predictors of linguistic style during multiword acquisition. Infant Behavior and Development, 20, 99-103.

Dixon, W. E., Jr., \& Smith, P. H. (2000). Links between temperament and language acquisition. Merrill-Palmer Quarterly, 46, 417-440.

Dunham, P. J., \& Dunham, F. (1992). Lexical development during middle infancy: A mutually driven infant-caregiver process. Developmental Psychology, 28, 414-420.

Dunham, P. J., Dunham, F., \& Curwin, A. (1993). Joint attentional states and lexical acquisition at 18 months. Developmental Psychology, 29, 827-831.

Fenson, L., Dale, P. S., Reznick, J. S., Bates, E., Thal, D. J., \& Pethick, S. (1994). Variability in early communicative development. Monographs of the Society for Research in Child Development, 59 (5, Serial No. 242).

Gartstein, M. A., \& Rothbart, M. K. (2003). Studying infant temperament via the Revised Infant Behavior Questionnaire. Infant Behavior and Development, 26, 64-86.

Goldsmith, H. H., \& Rothbart, M. K. (1991). Contemporary instruments for assessing early temperament by questionnaire and in the laboratory. In A. Angleitner \& J. Strelau (Eds.), Explorations in temperament: International perspectives on theory and measurement (pp. 249-272). New York: Plenum.

Karrass, J. (2002) Individual differences in temperament, joint attention and early language. (Doctoral dissertation, University of Notre Dame, 2002). Dissertation Abstracts International, 63(1-B), 566.

Karrass, J., \& Braungart-Rieker, J. (2003). Parenting and temperament as interacting agents in early language development. Parenting: Science and Practice, 3, 235-259.

Karrass, J., \& Braungart-Rieker, J. M. (2004). Infant negative emotionality and attachment: Implications for preschool intelligence. International Journal of Behavioral Development, 28, 221-229.

Kasari, C., Sigman, M., Mundy, P., \& Yirmiya, N. (1990). Affective sharing in the context of joint attention interactions of normal, autistic, and mentally retarded children. Journal of Autism \& Developmental Disorders, 20, 87-100.

Kubicek, L. F., Emde, R. N., \& Schmitz, S. (2001). Temperament, mental development, and language in the transition from infancy to early childhood. In R. N. Emde \& J. K. Hewitt (Eds.), Infancy to early childhood: Genetic and environmental influences on developmental change. New York: Oxford University Press.

Markus, J., Mundy, P., Morales, M., Delgado, C. E. F., \& Yale, M. (2000). Individual differences in infant skills as predictors of child-caregiver joint attention and language. Social Development, 9, 302-315. 
Matheny, A. P., Jr. (1989). Temperament and cognition: Relations between temperament and mental test scores. In G. A. Kohnstamm, J. E. Bates, \& M. K. Rothbart (Eds.), Temperament in childhood (pp. 263-282). Oxford, UK: Wiley.

Morales, M., Mundy, P., Delgado, C. E. F., Yale, M., Messinger, D., Neal, R., \& Schwartz, H. K. (2000a). Gaze following, temperament, and language development in 6-month olds: A replication and extension. Infant Behavior \& Development, 23, 231-236.

Morales, M., Mundy, P., Delgado, C. E. F., Yale, M., Messinger, D., Neal, R., \& Schwartz, H. K. (2000b). Responding to joint attention across the 6- through 24- month age period and early language acquisition. Journal of Applied Developmental Psychology, 21, 283-298.

Mundy, P., Delgado, C., Block, J., Venezia, M., Hogan, A., \& Seibert, J. (2003). A manual for the abridged Early Social Communication Scales (ESCS). Unpublished manuscript.

Mundy, P., \& Gomes, A. (1998). Individual differences in joint attention skill development in the second year. Infant Behavior and Development, 21, 469-482.

Mundy, P., Hogan, A., \& Doehring, P. (1996). A preliminary manual for the Abridged Early Social Communication Scales (ESCS). Unpublished manuscript.

Mundy, P., Kasari, C., \& Sigman, M. (1992). Nonverbal communication, affective sharing, and intersubjectivity. Infant Behavior \& Develompent, 15, 377-381.

Putnam, S. P., Ellis, L. K., \& Rothbart, M. K. (2001). The structure of temperament from infancy through adolescence. In A. Eliasz \& A. Angleitner (Eds.), Advances in research on temperament (pp. 165-182). Germany: Pabst Science.

Putman, S. P., Jones, L. B., \& Rothbart, M. K. (2002). The Early Childhood Behavior Questionnaire: Development, psychometrics, factor structure, and relations with behavior problems. Poster presented at the Biennial Meetings of the International Conference on Infant Studies, Toronto, CA, April 2002.

Rieser-Danner, L. (2003). Individual differences in infant fearfulness and cognitive performance: A testing, performance, or competence effect? Genetic, Social, and General Psychology Monographs, 129, 41-71.

Rothbart, M. K., \& Bates, J. E. (1998). Temperament. In W. Damon (Series Ed.) \& N. Eisenberg (Ed.), Handbook of child psychology: Vol. 3. Social, emotional, and personality development (5th Ed., pp. 105-176). New York: Wiley.

Rothbart, M. K., Chew, K. H., \& Gartstein, M. A. (2001). Assessment of temperament in early development. In L. T. Singer \& P. S. Zeskind (Eds.), Biobehavioral assessment of the infant (pp. 190-208). New York: Guilford.

Sheinkopf, S. J., Mundy, P., Claussen, A. H., \& Willoughby, J. (2004). Infant joint attention skill and preschool behavioral outcomes in at-risk children. Development and Psychopathology, 16, 273-291. 
Slomkowski, C. L., Nelson, K., Dunn, J., \& Plomin, R. (1992). Temperament and language: Relations from toddlerhood to middle childhood. Developmental Psychology, 28, 1098-1095.

Smith, P. H., Dixon, W. E., Jr., Jankowski, J. J., Sanscrainte, M. M., Davidson, B. K., Loboschefski, T. (1997). Longitudinal relationships between habituation and temperament in infancy. Merrill-Palmer Quarterly, 43, 291-304.

Thomas, A., Chess, S., \& Birch, H. G. (1968). Temperament and behavior disorders in children. New York: New York University Press.

Tomasello, T. (1995). Joint attention as social cognition. In C. Moore \& P. Dunham (Eds.), Joint attention: Its origins and role in development (pp. 103-129). Hillsdale, NJ: Erlbaum.

Tomasello, M., \& Farrar, M. J. (1986). Joint attention and early language. Child Development, 57, 1454-1463.

Ulvund, S. E., \& Smith, L. (1996). The predictive validity of nonverbal communicative skills in infants with perinatal hazards. Infant Behavior and Development, 19, 441-449.

Vaughan, A., Mundy, P., Block, J., Burnette, C., Delgado, C., Gomez, Y., Meyer, J., Neal, A. R., \& Pomares, Y. (2003). Child, caregiver, and temperament contributions to infant joint attention. Infancy, 4, 603-616. 